DOCUMENTO DE REFLEXIÓN
NO DERIVADO DE INVESTIGACIÓN

NO DERIVADO DE INVESTIGACION
Recibido: 5/10/2015

Revisado: 5/11/2015

Aprobado: 5/12/2015

\title{
LA EXCLUSIÓN DEL COLONIALISMO KDEL CAPITALISMO HA IMPEDIDO LA INTEGRACIÓN DE AMERICÁ LATINA E INCIDE EN EL FIN DEL RELATO EMANCIPATORIO Y EL DE SU IDENTIDAD
}

PABLO CASILLAS HERRERA

Docente Universidad de Guadalajara

\section{RESUMEN}

Poderosos actores no estatales están obteniendo un control sobre las vidas y bienestar de vastas poblaciones, sea el control de la salud, de la tierra, el agua potable, las semillas, los bosques o la calidad del medio ambiente. El Estado moderno liberal, el constitucional, que ha prevalecido está siendo reemplazado por obligaciones contractuales privatizadas y despolitizadas. Los acuerdos transatlanticos, los asiaticos y los rusos tienen esa direccionalidad. En las condiciones del nuevo gobierno indirecto, más que regular el conflicto social entre los ciudadanos, el pensamiento de la razon moderna de los abismos está llamado a suprimir el conflicto social y a ratificar el Estado de excepcion, sin ley. Bajo esta dirección la exclusión del colonialismo y del capitalismo neoliberal seguirán impidiendo la integración de América Latina y pretende dominar, controlar y sumprimir la única literatura de los saberes populares e indígenas, el relato emancipatorio, el de su identidad en suma, el pensamiento de los abismos moderno, el cual, ha sido llamado a ordenar la relación entre los ciudadanos, y entre ellos y el Estado, es ahora, en los dominios sociales con mayor presión de la lógica de apropiación/violencia, llamado a lidiar con ciudadanos como no ciudadanos, y con no ciudadanos como peligrosos salvajes naturales, como en colonialidad.

Palabras clave: Colonialismo, Capitalismo, Identidad.

\begin{abstract}
Powerful non-state actors are gaining control over the lives and well-being of vast populations, whether they control health, land, clean water, seeds, forests or the quality of the environment. The modern liberal state, the constitutional one that has prevailed is being replaced by privatized and depoliticized contractual obligations. The transatlantic agreements, the Asians and the Russians have that directionality. Under the conditions of the new indirect government, rather than regulating the social conflict between citizens, the thought of the modern reason of the abysses is called to suppress social conflict and to ratify the State of exception, without law. Under this direction, the exclusion of colonialism and neoliberal capitalism will continue to impede the integration of Latin
\end{abstract}


America and seeks to dominate, control and suppress the only literature of popular and indigenous knowledge, the emancipatory story, its identity in short, the thinking of the modern abyss, which has been called to order the relationship between citizens, and between them and the State, is now, in the social domains with greater pressure of the logic of appropriation / violence, called to deal with citizens as non-citizens, and with non-citizens as dangerous natural savages, as in coloniality.

Key words: Colonialism, Capitalism, Identity.

\section{Introducción}

A diferencia del pensamiento occidental, del cual he abordado con mayor detenimiento en la ponencia de hace dos años, me inscribo en el pensamiento latinoamericano que plantea la descolonización del saber y por ende se aleja de aquél. En esta concepción se encuentran autores como Boaventura de Sousa Santos, Aníbal Quijano, Edgardo Lander y John Holloway, entre otros. Esta descolonización ha implicado cuestionamientos al pensamiento crítico y a la política emancipadora de los movimientos sociales. Ambas corrientes se sitúan en el problema del ciclo del capitalismo, de la democracia y del Estado neoliberales. Mientras las del pensamiento crítico han considerado que se puede vivir con él en modelos que pueden denominarse como socialdemócratas, los de los movimientos sociales emancipatorios de América Latina, en cambio, se plantean cambios significativos en la concepción de democracia, el Estado y la Economía, manteniendo la prioridad de lo social y la ecología.

\section{La historia sin fin del capitalismo}

"Es tan difícil imaginar el fin del capitalismo como es difícil imaginar que el capitalismo no tenga fin", nos dice Boaventura de Sousa (De Sousa, 2010, 11). Esta dificultad ha fracturado el pensamiento crítico en dos vertientes que sostienen dos opciones políticas de izquierda distintas. La primera, ha dejado de imaginar el fin del capitalismo y, al contrario, ha centrado su atención en desarrollar un modus vivendi con el capitalismo que le permitiera minimizar los costos sociales de la acumulación capitalista. Esta concepción es la del keynesianismo - taylorista - fordista, la del Estado de bienestar y la del Estado desarrollista de los años sesenta del siglo pasado y la de la socialdemocracia latinoamericana, como las principales formas políticas de este modus vivendi. De ello, nos sobran las evidencias con Chile, Argentina y Brasil. En este último caso, Lula es hoy el ejemplo más elocuente de esta vertiente de la tradición crítica y de la política que ella sostiene. Es una socialdemocracia de nuevo tipo, no asentada en derechos universales sino en políticas significativas a los grupos sociales considerados más vulnerables. Logró sacar a más de 50 millones de la pobreza. Es también un Estado neodesarrollista que articula el nacionalismo económico mitigado con la obediencia resignada a la ortodoxia del comercio internacional y de las instituciones del capitalismo global.

La otra vertiente de la tradición crítica se aleja significativamente de la primera, imagina y actúa de como es el fin del capitalismo. La dificultad es doble ya que, por un lado, reside en imaginar alternativas poscapitalistas después 
del colapso del «socialismo real» y, por otro, implica imaginar alternativas precapitalistas anteriores a la conquista y al colonialismo. En estas alternativas se encuentran la del «socialismo del siglo XXI», pero la de mayor profundidad ha sido la del Sumak Kawsay. Los procesos políticos en curso hoy en día en Venezuela, Ecuador y Bolivia representan significativamente estas vertientes. Esta dificultad de la imaginación-actuación política no está igualmente distribuida en el campo político: si los gobiernos imaginan el poscapitalismo a partir del capitalismo, los movimientos indígenas imaginan el poscapitalismo a partir del precapitalismo. Pero ni unos ni otros imaginan el capitalismo sin el colonialismo interno, pues constituye un problema profundo: de estructura mental.

Sin embargo, la coexistencia de estas dos vertientes de imaginación y actuación política es de lo más creativo que caracteriza al continente latinoamericano en este período.

\section{La historia sin fin del colonialismo}

"Es tan difícil imaginar el fin del colonialismo como es difícil imaginar que el colonialismo no tenga fin", nos dice Boaventura de Sousa (De Sousa, 2010, 11). De nueva cuenta nos encontramos con dos vertientes del pensamiento crítico: una que ha dejado de imaginar y actuar el fin del colonialismo, incluso lo ha estimulado con la apertura del mercado internacional, en una apertura política del Estado, y con ello el resultado ha sido la negación de la existencia misma del colonialismo, dando paso al neocolonialismo. Esta vertiente del pensamiento crítico se centra en la lucha de clases y no reconoce la validez de la lucha étnico-racial. Al contrario, valora el mestizaje que caracteriza es- pecíficamente al colonialismo ibérico como manifestación adicional de la superación del colonialismo. Paralelamente, la idea de democracia racial es celebrada como realidad y no defendida como aspiración.

Al contrario, la otra vertiente de la tradición crítica emancipatoria parte del presupuesto de que el proceso histórico que condujo a las independencias es la prueba de que el patrimonialismo y el colonialismo interno no solo se mantuvieran después de las independencias, sino que en algunos casos incluso se agravaran. La dificultad de imaginar la alternativa al colonialismo reside en que el colonialismo interno no es solo ni principalmente una política de Estado, como sucedía durante el colonialismo de ocupación extranjera; es una gramática social muy vasta que atraviesa la sociabilidad, el espacio público y el espacio privado, la cultura, las mentalidades y las subjetividades. Es, en resumen, un modo de vivir y convivir muchas veces compartido por quienes se benefician de él y por los que lo sufren. Para esta vertiente de la tradición crítica la lucha anticapitalista tiene que ser conducida de modo paralelo a la lucha anticolonialista. La dominación de clase y la dominación étnico-racial se alimentan mutuamente, por tanto, la lucha por la igualdad no puede estar separada de la lucha por el reconocimiento de la diferencia. Para esta vertiente el desafío del poscolonialismo tiene en el continente un carácter originario. Nadie lo formuló de manera tan elocuente como José Mariátegui cuando, al referirse a la sociedad peruana (pero aplicable a las otras sociedades latinoamericanas), hablaba del pecado original de la conquista: «el pecado de haber nacido y haberse formado sin el indio y contra el indio» (s/f [1925]: 208). 


\section{La marea de las categorías}

Durante algún tiempo la teoría crítica era «propietaria» de un conjunto vasto de categorías que marcaban su diferencia con relación a las teorías convencionales. Entre ellos: socialismo, comunismo, dependencia, lucha de clases, alienación, participación, frente de masas, etcétera. Hoy, aparentemente, casi todas las categorías desaparecieron. En los últimos treinta años la tradición crítica eurocéntrica pasó a caracterizarse y distinguirse por vía de los adjetivos con que califica las categorías propias de las teorías convencionales. Así, por ejemplo, si la teoría convencional habla de desarrollo, la teoría crítica hace referencia a desarrollo alternativo, democrático o sostenible; si la teoría convencional habla de democracia, la teoría crítica plantea democracia radical, participativa o deliberativa; lo mismo con cosmopolitismo, que pasa a llamarse cosmopolitismo subalterno, de oposición o insurgente, enraizado; y con los derechos humanos, que se convierten en derechos humanos radicales, colectivos, interculturales. Hay que analizar con cuidado este cambio. Las categorías hegemónicas no son, en el plano pragmático, una propiedad inalienable del pensamiento neoliberal. Una de las dimensiones del contexto actual del continente es precisamente la capacidad que los movimientos sociales e indígenas han mostrado para usar de modo contrahegemónico y para fines contrahegemónicos categorías hegemónicas. Hay que tener en cuenta que las categorías aún establecen el horizonte intelectual y político que define no solamente lo que es decible, creíble, legítimo o realista sino también lo que es indecible, increíble, ilegítimo o irrealista. La teoría crítica convencional latinoamericana asume este debate en tér- minos convencionales, no así la teoría de los procesos emancipatorios, que la imaginación y acción, en el rescate de su propia memoria, cultura y lingüística, trascienden no sólo los no imaginarios de la teoría crítica convencional sino claramente de la teoría neo-liberal, con categorías como Sumak Kawsay, Estado plurinacional.

\section{Los espejos de la teoría y la práctica}

La tradición critica eurocéntrica reside en la enorme discrepancia entre lo que está previsto en la teoría y las prácticas más transformadoras en curso en el continente. En los últimos treinta años las luchas más avanzadas fueron protagonizadas por grupos sociales (indígenas, campesinos, afrodescendientes, mujeres, desempleados, piqueteros, etcétera) cuya presencia en la historia no fue prevista por la teoría crítica eurocéntrica. Se organizaron muchas veces con formas (movimientos sociales, comunidades eclesiales de base, piquetes, autogobierno, organizaciones económicas populares, campesinos) muy distintas de las privilegiadas por la teoría: el partido y el sindicato. No habitan los centros urbanos industriales sino lugares remotos en las alturas de los Andes o en llanuras de la selva amazónica. Expresan sus luchas muchas veces en sus idiomas comunales y no en ninguna de las lenguas coloniales. Y cuando sus demandas y aspiraciones son traducidas en las lenguas coloniales o neocoloniales, no emergen los términos familiares de socialismo, derechos humanos, democracia o desarrollo, sino dignidad, respeto, territorio, autogobierno, el buen vivir, la Madre Tierra, el derecho a la diferencia, etcétera. Categorías que incluso son del argot occidental pero que tienen un 
contenido poshegemónico en los procesos emancipatorios. Aquí, la ontología adquiere una historidad y un sentido de apropiación y pertenencia radicalmente diferente. La constancia de este antireflejo de imágenes entre teoría y práctica tuvo un momento de gran visibilidad en el escenario latinoamericano. Desde el Ejército Zapatista de Liberación Nacional (EZLN) en Chiapas a la elección de Lula en Brasil; desde los piqueteros argentinos al Movimiento Sin Tierra (MST); desde los movimientos indígenas de Bolivia y Ecuador al Frente Amplio de Uruguay, a las sucesivas victorias de Hugo Chávez en Venezuela y a la elección de Evo Morales en Bolivia, de Fernando Lugo en Paraguay y de José Mujica en Uruguay; desde la lucha continental contra el Área de Libre Comercio de las Américas (ALCA) al proyecto de integración regional alternativo liderado por Hugo Chávez la Alternativa Bolivariana para las Américas (ALBA), nos encontramos con prácticas políticas que se reconocen como emancipadoras, pero que no estaban previstas por las grandes tradiciones teóricas de la izquierda eurocéntrica o que incluso las contradicen.

El ensayo de la ceguera de la teoría, como diría José Saramago, acaba en la invisibilidad de la práctica, mientras que el ensayo de la ceguera de la práctica acaba en la irrelevancia de la teoría, y en consecuencia la pérdida total de la lucidez. El ensayo de la ceguera de la teoría se puede observar en la manera en que los partidos convencionales de la izquierda, y los intelectuales a su servicio, se han negado a ver la aristocracia de los partidos políticos y la pérdida de sus identidades ideológicas e históricas. El ensayo de la ceguera de la práctica, a su vez, está manifiestamente presente en el desdén mostrado por la gran mayoría de las izquierdas convencionales hacia la rica tradición teórica de la izquierda eurocéntrica y su total desprecio por su renovación. Este desencuentro mutuo produce, en el terreno de la práctica, una oscilación extrema entre la espontaneidad revolucionaria o pseudo-revolucionaria y un posibilismo autocensurado e inocuo; y, en el terreno de la teoría, una oscilación igualmente extrema entre un celo reconstructivo post factum y una arrogante indiferencia por lo que no está incluido en semejante reconstrucción.

En consecuencia lo que podria ser el ensayo de la lucidez con los movimientos sociales e indígenas es negado. En estas condiciones, la relación entre teoría y práctica asume características extrañas. Por una parte, la teoría deja de estar al servicio de las prácticas futuras que potencialmente contiene, y sirve más bien para legitimar (o no) las prácticas pasadas que han surgido a pesar de sí misma. Deja de ser una orientación para convertirse en una ratificación de los éxitos obtenidos por omisión o confirmación de fracasos preanunciados. Por otra parte, la práctica se justifica a sí misma recurriendo a un crucigrama teórico centrado en las necesidades del momento, formado por conceptos y lenguajes heterogéneos que desde el punto de vista de la teoría, no son más que racionalizaciones oportunistas o ejercicios retóricos. Desde el punto de vista de la teoría, el crucigrama teórico nunca se califica como teoría. Desde el punto de vista de la práctica, una teorización a posteriori es una mera tautología.

Las causas de esta relación idílica entre la teoría y la práctica son múltiples, pero la más importante es que mientras la teoría crítica eurocéntrica fue 
construida en algunos países europeos (Alemania, Inglaterra, Francia, Rusia e Italia) con el objetivo de influenciar las luchas progresistas del momento en esa región del mundo, las luchas más innovadoras y transformadoras, en camibio hoy día vienen ocurriendo en gran parte del Sur de América Latina en el contexto de realidades socio-políticoculturales muy distintas. Sin embargo, la distancia entre teoría y práctica no es solamente el producto de las diferencias de contextos. Es una distancia más bien epistemológica o hasta ontológica. Los movimientos del continente latinoamericano, más allá de los contextos, construyen sus luchas basándose en conocimientos ancestrales, populares, espirituales que siempre fueron ajenos al cientismo propio de la teoría crítica eurocéntrica. Por otro lado, sus concepciones ontológicas sobre el ser y la vida son muy distintas de la noción del tiempo y del individualismo occidental. Los seres son comunidades de seres antes que individuos; en esas comunidades están presentes y vivos los antepasados así como los animales y la Madre Tierra. Estamos ante cosmovisiones no occidentales que obligan a un trabajo de traducción intercultural para poder ser entendidas y valoradas.

La distancia que propongo con relación a la tradición crítica eurocéntrica tiene por objetivo abrir espacios analíticos para realidades «sorprendentes» con categorías nuevas, porque son nuevas las realidades o porque hasta ahora fueron producidas como no existentes, donde puedan brotar emergencias libertadoras de pensamientos y mentalidades diferentes no necesariamente occidentales.

\section{La distancia con relación a la tradición crítica eurocéntrica}

Tomar esta distancia no significa descartar o desechar la historia, toda esta tradición tan rica, y mucho menos ignorar las posibilidades históricas de emancipación social de la modernidad occidental. Nada de eso, por el contrario, significa asumir nuestro tiempo, en el continente latinoamericano, como un tiempo que revela una característica transicional inédita que podemos formular como problemas modernos para los cuales no hay soluciones modernas. Y que es necesario trascender. Este es el punto de referencia y de quiebre. Los problemas modernos de la igualdad y de la libertad persisten. Sin embargo, las soluciones modernas propuestas por el liberalismo y también por el marxismo ya no sirven, incluso si son llevadas a su máxima conciencia posible (para usar una expresión de Lucien Goldmann) como es el caso de la magistral reconstrucción intelectual de la modernidad occidental propuesta por Habermas. Los límites de tal reconstrucción están inscritos en la versión dominante de la modernidad occidental de que parte Habermas, que es, de hecho, una segunda modernidad construida a partir de la primera modernidad. Lo que caracteriza la segunda modernidad y le confiere su carácter dominante es la línea abismal que establece entre las sociedades metropolitanas (Europa) y las sociedades coloniales.

Esta línea abismal atraviesa todo el pensamiento de Habermas. Su extraordinaria lucidez permite verla, pero no superarla. Su teoría de la acción comunicativa, en cuanto nuevo modelo universal de racionalidad discursiva, es bien conocida. Habermas entiende que esa teoría constituye un telos de desa- 
rrollo para toda la humanidad y que con ella es posible rehusar tanto el relativismo como el eclecticismo.

\section{Del pensamiento occidental de los abismos a una ecología de saberes}

El pensamiento occidental moderno es un pensamiento de abismos, parodiando a Boaventura de Sousa. Este consiste en un sistema de distinciones visibles e invisibles, de espejos visibles y enterrados, emulando a Carlos Fuentes. Las invisibles constituyen el fundamento de las visibles, es decir son el significado y el predicado de un sujeto sobre la negación de la gramática de otro sujeto, aunque Carlos Fuentes diría que son la constante encrucijada de lo que se quiere ser y no se puede ser. De la imagen que refleja el espejo enterrado: la negación y vergüenza del pasado. La historia del colonialismo y del surgimiento de las guerras de independencia dan cuenta de ello. La encrucijada es tal que "la imagen que refleja el espejo enterrado de negación, horror y vergüenza" desaparece como realidad neocolonial, la de nuestros días, se convierte en no existente, y de hecho es producido como no existente, en una nueva negación. No existente significa no existir en ninguna forma relevante o comprensible de ser. Así, podemos negar las inclusiones del capitalismo neoliberal con aperturas económicas y políticas en las que determinan los rumbos de nuestros países latinoamericanos con resultados positivos de participación de las transnacionales y de los organismos internacionales, o con Convenios Transnacionales, como versiones de continuidad del ALCA, en los que se jura y perjura el progreso y justifica la democracia liberal montada en el capitalismo neoliberal. Esto es lo que carac- teriza al pensamiento occidental de los abismos y es pues la imposibilidad de la copresencia con la de los saberes emancipatorios. Estos prevalecen en la medida en que angosta el campo de la realidad relevante. Más allá de esto, solo está la no existencia, la invisibilidad, la ausencia no dialéctica.

Podríamos considerar, entonces, a la modernidad occidental como un paradigma sociopolítico fundado en la tensión entre regulación social y emancipación social. Y la relación dialéctica se daría a través de la distinción visible que fundamenta todos los conflictos modernos, en términos de problemas sustantivos y en términos de procedimientos. Pero por debajo de esta distinción existe otra, una distinción invisible, sobre la cual se funda la anterior. Esa distinción invisible es la distinción entre sociedades metropolitanas y territorios coloniales. En efecto, la dicotomía regulación-emancipación solo se aplica a las sociedades metropolitanas. Sería impensable aplicarla a los territorios coloniales. La dicotomía regulaciónemancipación no tuvo un lugar concebible en estos territorios, sobretodo cuando se trata de estructuras mentales. Allí, otra dicotomía fue la aplicada, la dicotomía entre apropiación-violencia sobre las razas, como diría Aníbal Quijano, la cual, por el contrario, sería inconcebible sin el pensamiento occidental, generando uno de los abismos: la negación.

En el campo del conocimiento, el pensamiento abismal consiste en conceder a la ciencia moderna el monopolio de la distinción universal entre lo verdadero y lo falso, en detrimento de dos cuerpos alternativos de conocimiento: la filosofía y la teología. El carácter exclusivista de este monopolio se 
encuentra en el centro de las disputas epistemológicas modernas entre formas de verdad científicas y no científicas. Puesto que la validez universal de una verdad científica es obviamente siempre muy relativa, dado que puede ser comprobada solamente en lo referente a ciertas clases de objetos bajo determinadas circunstancias y establecida por ciertos métodos, ¿cómo se relaciona esto con otras posibles verdades que puedan demandar un estatus mayor pero que no se puedan establecer según métodos científicos, tales como la razón y la verdad filosófica, o como la fe y la verdad religiosa?

Estas tensiones entre ciencia, filosofía y teología han llegado a ser altamente visibles pero todas ellas tienen lugar en el pensamiento occidental de los precipicios. Su visibilidad se erige sobre la invisibilidad de otras formas de conocimiento que no pueden ser adaptadas a ninguna de esas formas de conocimiento: de la racionalidad y de la subjetividad objetivadas. Me refiero a conocimientos populares, laicos, plebeyos, campesinos o indígenas, que son los saberes emancipatorios. Desaparecen como conocimientos relevantes o conmensurables porque se encuentran más allá de la verdad y de la falsedad. En otra razón y en otra compresión. Es inimaginable aplicarlas no solo la distinción científica de lo verdadero o falso, sino también las verdades científicas inaveriguables de la filosofía y la teología que constituyen todos los conocimientos occidentales de los abismos. Al otro lado, en el de los saberes emancipatorios no hay un conocimiento real; hay creencias, opiniones, magia, idolatría, comprensiones intuitivas o subjetivas, las cuales, en la mayoría de los casos, se convierten en objetos o materias primas para las investigacio- nes científicas. En objetos de investigación cuando no de satanización. Así, el conocimiento de los precipios separa la ciencia de la filosofía y de la teología, crece sobre una línea invisible abismal que coloca, de un lado, la ciencia, la filosofía y la teología y, del otro, conocimientos, hechos inconmensurables e incomprensibles, por no obedecer ni a los métodos científicos de la verdad ni a los de los conocimientos, reconocidos como alternativos, en el reino de la filosofía y la teología.

En el campo del derecho moderno, que acoraza al Estado moderno, está determinado por lo que se considera legal o ilegal de acuerdo con el estado oficial o con el derecho internacional. Lo legal y lo ilegal son las únicas dos formas relevantes de existir ante el derecho y, por esa razón, la distinción entre las dos es una distinción universal. Esta dicotomía central abandona todo el territorio social donde la dicotomía podría ser impensable como un principio organizativo, ese es, el territorio sin ley, lo legal, lo no legal e incluso lo legal o lo ilegal de acuerdo con el derecho no reconocido oficialmente. Así, el pensamiento de los abismos que separa el reino del derecho del reino del no derecho fundamenta la dicotomía visible entre lo legal y lo ilegal que organiza, en este lado de la línea, el reino del derecho.

Desde mediados del siglo XVI en adelante, el debate legal y político entre los Estados europeos concerniente al Nuevo Mundo está centrado en la línea legal global, esto es, en la determinación de lo colonial, no en el orden interno de lo colonial. Por el contrario, lo colonial es el estado de naturaleza donde las instituciones de la sociedad civil no tienen lugar. Thomas Hobbes se refiere explícitamente a la «población salvaje en muchos lugares de América» como 
ejemplos del estado de naturaleza (1985 [1651]: 187), y asimismo John Locke piensa cuando escribe Del Gobierno civil: «En el principio todo el mundo era América» (1946 [1690]: §49). Lo colonial es así el punto oculto sobre el cual las concepciones modernas de conocimiento y derecho son construidas. Las teorías del contrato social de los siglos XVII y XVIII son tan importantes tanto por lo que sostienen como por lo que silencian. Lo que dicen es que los individuos modernos, los hombres metropolitanos, entran en el contrato social para abandonar el estado de naturaleza y formar la sociedad civil. Lo que no dicen es que de este modo está siendo creada una masiva región mundial de estado de naturaleza, un estado de naturaleza al cual millones de seres humanos son condenados y dejados sin alguna posibilidad de escapar vía la creación de una sociedad civil.

La modernidad occidental, más allá de significar el abandono del estado de naturaleza y el paso a la sociedad civil, significa la coexistencia de ambos, sociedad civil y estado de naturaleza, separados por una línea abismal donde el ojo hegemónico, localizado en la sociedad civil, cesa de mirar y, de hecho declara como no existente el estado de naturaleza. El presente que va siendo creado al lado del pensamiento occidental se hace invisible al ser reconceptualizado como el pasado irreversible que es nuestro presente. El contacto hegemónico se convierte simultáneamente en contemporaneidad. Esto disfraza el pasado para hacer espacio a un único y homogéneo futuro.

En tanto que los saberes emancipatorios albergan solo prácticas mágicas o idólatras incomprensibles. La extrañeza completa de dichas prácticas llevó a la negación de la naturaleza humana. En la base de sus refinadas concepciones de humanidad o dignidad humana, los humanistas alcanzaron la conclusión de que los salvajes eran subhumanos. ¿Tienen alma los indios? —era la cuestión. Cuando el Papa Pablo III respondió afirmativamente en su bula Sublimis Deus de 1537, lo hizo por convencimiento de que la población indígena tenía alma como un receptáculo vacío, un anima nullius, muy similar a la terra nullius. El concepto de vacío jurídico fue el que justificó la invasión y ocupación de los territorios indígenas.

Con base en estas concepciones abismales legales y epistemológicas, la universalidad de la tensión entre regulación y emancipación, de acuerdo al pensamiento occidental, no se contradice con la tensión entre apropiación y violencia aplicada a los saberes emancipatorios. Apropiación y violencia toman diferentes formas en la lógica del derecho y en la epistemológica de los abismos. Pero, en general, apropiación implica incorporación, cooptación y asimilación, mientras que violencia implica destrucción física, material, cultural y humana. Esto avanza sin decir que apropiación y violencia están profundamente entrelazadas. En la comprensión del conocimiento, la apropiación se extiende desde el uso de los nativos como guías y el uso de mitos y ceremonias locales como instrumentos de conversión, hasta la expropiación del conocimiento indígena de la biodiversidad; mientras la violencia se extiende desde la prohibición del uso de lenguas nativas en espacios públicos y la adopción forzada de nombres cristianos, la conversión y destrucción de lugares ceremoniales y símbolos, a todas las formas de discriminación racial y cultural. Como mantiene la ley, la tensión entre apropiación y violencia es particularmente compleja a causa de su relación directa con la extracción de valor: comercio de esclavos y trabajo forzado, uso instrumental del derecho de costumbres y la autoridad en el gobierno indirecto, expropiación 
de recursos naturales, desplazamientos masivos de poblaciones, guerras y tratados desiguales, diferentes formas de apartheid y asimilación forzada, etcétera. Se acerca el pasado con el presente, la colonia con la neocolonialidad, lo anormal en lo normal. Mientras la lógica regulación/emancipación es impensable sin la distinción matriz entre el derecho de las personas y el derecho de las cosas, la lógica de apropiación/violencia solo reconoce el derecho de las cosas, de ambas cosas, humanas y no humanas. La típica versión casi ideal de este derecho es la ley del «Estado Libre del Congo» bajo el Rey Leopoldo II de Bélgica.

Existe, por lo tanto, una razón moderna dual: una razón legal y una razón epistemológica. En la razón moderna de los abismos o de los precipicios es el reino de más allá de la legalidad y la ilegalidad (sin ley), de más allá de la verdad y la falsedad (creencias, idolatría y magia incomprensible). Juntas, estas formas de negación radical resultan en una ausencia radical, la ausencia de humanidad, la subhumanidad moderna. La exclusión es así radical y no existente, como subhumanos no son candidatos concebibles para la inclusión social. La humanidad moderna no es concebible sin la subhumanidad moderna. La negación de una parte de la humanidad es un sacrificio, ahí se encuentra la condición de la afirmación de esa otra parte de la humanidad la cual se considera a sí misma como universal.

Mi argumento en este texto es que esto es tan verdadero hoy en día en la colonialidad como en el período colonial. El pensamiento moderno occidental avanza operando sobre líneas abismales que dividen lo humano de lo subhumano de tal modo que los principios humanos no quedan comprometidos por prácticas inhumanas. Las colonias proveyeron un modelo de exclusión radical que prevalece hoy en día en el pensamiento y práctica occidental moderna como lo hicieron durante el ciclo colonial. Hoy como entonces, la creación y la negación del otro lado de la línea son constitutivas de los principios y prácticas hegemónicas. Hoy como entonces, la imposibilidad de la copresencia entre los dos lados de la línea se convierte en suprema. Hoy como entonces, la civilidad legal y política del pensamiento occidental presupone la existencia de una completa incivilidad en los saberes emacipatorios latinoamericanos. Sostengo, primero, que la tensión entre regulación y emancipación continúa coexistiendo con la tensión entre apropiación y violencia de tal modo que la universalidad de la primera tensión no se contradice con la existencia de la segunda; segundo, que el pensamiento moderno de los abismos o de los precipicios continúan estructurando el conocimiento moderno y el derecho moderno; y, tercero, que esas dos líneas de los abismos y precipicios son constitutivas de las relaciones políticas y culturales basadas en Occidente, y de las interacciones en el sistema mundo moderno. En suma, sostengo que la razón moderna ha sobrevivido porque se ha impuesto y se sigue imponiendo, como sucedió en el Viejo del Nuevo Mundo. La injusticia social global está, por lo tanto, íntimamente unida a la injusticia cognitiva global. La batalla por la justicia social global debe, por lo tanto, ser también una batalla por la justicia cognitiva global. Para alcanzar el éxito, esta batalla requiere un nuevo tipo de pensamiento, un pensamiento poscolonial, poscapitalista, posracional, posoccidental, con otra epistemología y otra ontología. 
Los abismos entre regulación/ emancipación y apropiación/violencia

La permanencia del pensamiento occidental moderno en la razón de la justicia global y de la razón epistemológica global a través del período moderno no significa que hayan permanecido fijas. Históricamente, han sido cambiantes. Sin embargo, estos cambios no han sido de mutuo propio, han sido respuesta al paradigma de apropiación/violencia y regulación/emancipación. En los últimos tiempos las líneas globales sufrieron sacudidas sistémicas. Una de ellas tuvo lugar con las luchas anticoloniales y los procesos de independencia. Los procesos de los movimientos de emancipación se han erguido contra la exclusión radical, las poblaciones que habían sido sometidas al paradigma de la apropiación/ violencia, se organizaron y clamaron el derecho de ser incluidas en el paradigma de la regulación/emancipación. Por un tiempo, el paradigma de la apropiación/ violencia parecía tener su fin, y así hizo la división abismal entre el pensamiento occidental moderno y los movimientos de emacipación. Cada una de las concepciones modernas, la epistemológica y la jurídica, parecían estar moviéndose de acuerdo con su propia lógica, pero ambas en la misma dirección: sus movimientos parecían converger en la contracción y en última instancia en la eliminación de los saberes emancipatorios. Sin embargo, esto no fue lo que ocurrió, como mostraron la teoría de la dependencia, la teoría del sistema-mundo, y los estudios poscoloniales.

En este texto, el análisis de otro momento de crisis sistémica en las líneas de la justicia global y de la razón epistemológica global se puede apreciar hacia algo diferente, en una dirección novedosa y con cosas nuevas en los procesos emancipatorios. La lógica de la apropiación/violencia ha ido ganan- do fuerza en detrimento de la lógica de regulación/emancipación. Hasta tal punto que el dominio de la regulación/ emancipación está no solo contrayéndose sino contaminándose internamente por la lógica de la apropiación/violencia.

La complejidad de este movimiento es difícil de develar tal y como se presenta ante nuestros ojos, y nuestros ojos nos pueden ayudar haciendo la lectura solo desde la razón occidental si no se crean los puentes a los abismos hacia los saberes emancipatorios. Para ello la lectura no puede ser individual es necesariamente colectiva, porque su compresión no puede ser individual sino colectiva. Este alejamiento del pensamiento moderno nos motiva a un esfuerzo colectivo en el que se desarrolla una epistemología colectiva. Así nos encontramos con este giro epistemológico hoy día, construida desde los movimientos emancipatorios con una gran participación-acción latinoamericana, en el que este movimiento está hecho de un movimiento principal y un contramovimiento subalterno con visos posneocoloniales. El retorno del colonialismo como neocolonialidad del poder es la respuesta a los abismos que había generado en la modernidad y que significa una forma de dominación económica, política y cultural, expresada en formas perversas del capitalismo como dominación terrorista; de migración por desempleo, guerra de dominación geopolítica, de indocumentados y por exclusión racial y económica. Estas figuras, dibujan la emergencia de una nueva forma de Estado de derecho, el Estado de excepción, el cual, contrariamente a las viejas formas de Estado de sitio o Estado de emergencia, restringe derechos de la democracia liberal bajo la premisa de salvaguardarlos o incluso expandirlos. El colonialismo que retorna es de hecho un nuevo colonialismo de los precipicios. Esta vez, el colonialismo retorna no solo 
en los territorios coloniales anteriores sino también en las sociedades metropolitanas en sus estructuras mentales. Aquí reside la gran transgresión, pues la colonialidad del período colonial clásico en ningún caso podía entrar en las sociedades metropolitanas, en el que se podía tener una mayor resistencia a las formas de dominación cognitivas occidentales. Hoy, se penetra en los espacios metropolitanos que fueron demarcados desde el comienzo de la modernidad occidental como una normalidad, y en cambio en las zonas rurales están ahora emergiendo resistencias como movimientos emancipatorios. No me refiero solo a los llamados movimientos antisistémicos sino también a los movimientos de autoseguridad comunitaria, en la que rompen con la lógica de la justicia de la razón moderna. Parece que la modernidad occidental solo puede expandirse globalmente en la medida en que viola todos los principios sobre los cuales históricamente se ha fundamentado la legitimidad del paradigma regulación/emancipación. Los derechos humanos son así violados con objeto de ser defendidos, la democracia es destruida para salvaguardar la democracia, la vida es eliminada para preservar la vida. Los abismos de la razón moderna como democracia y de capitalismo neoliberal están siendo trazadas en un sentido literal y metafórico en su aplicación. Hay un retorno del colonizador que podría denominarse Organismos Internacionales, transnacionales o Imperios en el que están reordenando geopolíticamente al mundo hacia un nuevo gobierno indirecto, en el que está el Estado que se retira de la regulación social y cuyos servicios públicos son privatizados, pero también en el que está reorganizando la economía política, la migratoria, la de las drogas y la de los mercados. Poderosos actores no estatales están obteniendo un control sobre las vidas y bienestar de vastas po- blaciones, sea el control de la salud, de la tierra, el agua potable, las semillas, los bosques o la calidad del medio ambiente. El Estado moderno liberal, el constitucional, que ha prevalecido está siendo reemplazado por obligaciones contractuales privatizadas y despolitizadas. Los acuerdos trans atlánticos, los asiáticos y los rusos tienen esa direccionalidad. En las condiciones del nuevo gobierno indirecto, más que regular el conflicto social entre los ciudadanos, el pensamiento de la razón moderna de los abismos está llamado a suprimir el conflicto social y a ratificar el Estado de excepción, sin ley. Bajo esta dirección la exclusión del colonialismo y del capitalismo neoliberal seguirán impidiendo la integración de América Latina y pretende dominar, controlar y suprimir la única literatura de los saberes populares e indígenas, el relato emancipatorio, el de su identidad en suma, el pensamiento de los abismos moderno, el cual, ha sido llamado a ordenar la relación entre los ciudadanos, y entre ellos y el Estado, es ahora, en los dominios sociales con mayor presión de la lógica de apropiación/violencia, llamado a lidiar con ciudadanos como no ciudadanos, y con no ciudadanos como peligrosos salvajes naturales, como en colonialidad. El exterminio social coexiste con la democracia liberal, el Estado de excepción coexiste con la normalidad constitucional, la sociedad civil coexiste con el Estado de naturaleza, el gobierno indirecto coexiste con el gobierno de la ley. Lejos de ser una perversión de alguna legislación normal original, este es el diseño original de la epistemología moderna y la legalidad, que ha impuesto la razón moderna de la neocolonialidad y de la razón moderna global. 


\section{BIBLIOGRAFÍA}

De Sousa Boaventura, Descolonizar el saber, reinventar el poder. Uruguay: Trilce Editorial.

De Sousa Boaventura, Refundación del estado en América Latina: Perspectivas desde una epistemología del sur. México: Siglo XXI Editores.

Holloway John, Cambiar el mundo sin tomar el poder. El significado de la revolución hoy, Universidad de Puebla, México y Revista Herramienta, Argentina. 2002

Lander Edgardo. La colonialidad del saber: eurocentrismo y ciencias sociales. Perspectivas latinoamericanas (compilador, 2000)

Lander Edgardo. La democracia en las ciencias sociales latinoamericanas contemporáneas (1997)

Lander Edgardo. Modernidad y Universalismo. Pensamiento crítico: un diálogo interregional (editor, 1991).

Lander Edgardo. Neoliberalismo, sociedad civil y democracia. Ensayos sobre América Latina y Venezuela (1995)

Quijano Aníbal. Crisis imperialista y clase obrera en América Latina. Lima: Edición del autor, 1974.

Quijano Aníbal. Imperialismo y marginalidad en América Latina. Lima, Mosca Azul Ediciones, 1977.

Quijano Aníbal. Modernidad, identidad y utopía en América Latina. Lima, Sociedad y Política Ediciones, 1988

Quijano Aníbal. Nacionalismo, neoimperialismo y militarismo en el Perú. Buenos Aires, Periferia, 1971. 